Muschalla, B., Henning, A., Haake, T., Cornetz, K., \& Olbrich, D. (2019). Mental Health Problem or Workplace Problem or Something Else: What contributes to Work

Perception? Disability and Rehabilitation, $x x$, xx-xx. doi: 10.1080/09638288.2018.1501099.

Mental Health Problem or Workplace Problem or Something Else: What contributes to Work Perception?

Running head: MENTAL PROBLEMS, WORK PROBLEMS AND WORK PERCEPTION

Research Report for publication in: Disability and Rehabilitation

Beate Muschalla ${ }^{1}$, Anne Henning ${ }^{2}$, Tim Woody Haake ${ }^{3}$, Kathrin Cornetz $^{3}$, Dieter Olbrich ${ }^{4}$

${ }^{1}$ Technische Universität Braunschweig, Department of Psychology, Germany

${ }^{2}$ Freie Universität Berlin, Department of Psychology, Germany

${ }^{3}$ University Potsdam, Department of Psychology, Germany

${ }^{4}$ Rehabilitation Center Bad Salzuflen, Department Psychosomatic, Germany

Address for correspondence:

Prof. Dr. Beate Muschalla

Technische Universität Braunschweig, Psychotherapie und Diagnostik,

Humboldtstraße 33, 38106 Braunschweig

Email: beate.muschalla@gmx.de 
Mental Health Problem or Workplace Problem or Something Else: What contributes to Work Perception?

\begin{abstract}
Work perception is an important predictor for work ability and therefore of interest for rehabilitation. Until now it is unclear to which extent different psychological aspects explain work perception. This study investigates in which way workplace problems on the one hand, and mental health and coping on the other hand, contribute to work perception.
\end{abstract}

A heterogeneous sample of 384 persons in working age with and without mental health problems was recruited. Participants gave self-reports on workplace problems, mental health problems, work-coping, work-anxiety, and work perception.

Persons with mental health problems and workplace problems $(\mathrm{M}+\mathrm{W})$ perceive the highest degree of work demands, followed by persons with workplace problems but without mental health problems $(\mathrm{NM}+\mathrm{W})$. Work-anxiety appeared as the strongest factor explaining perception of high work demands, whereas general mental health problems did not contribute significantly to variance explanation.

Persons with specific mental health problems in terms of work-anxiety may be expected to perceive higher work demands. They may be detected when asking for work perception, e.g. within the frame of return-to-work interventions in rehabilitation, or in occupational health settings by mental hazard analysis.

\title{
Keywords:
}

Work ability, work anxiety, workplace, mental disorders, rehabilitation, work perception 


\section{Mental Health Problem or Workplace Problem or Something Else: What contributes to Work Perception?}

Work perception is an important indicator for work ability [1], which is a main topic in all rehabilitation settings. Perceived negative or problematic work characteristics, especially high mental work demands, lack of autonomy, poor physical work environment come along with reduced subjective work ability [2]. Work perception may be explained by diverse factors, e.g. the employee's expectations about good work, and his/her qualification level and coping resources. In our modern work environments, especially the mental health condition and its relation to work characteristics come into focus [3]. Until now it is unclear to which extent workplace problems on the one hand and personal mental health factors (including coping) on the other hand explain work perception. This study investigates for the first time in which way workplace problems and mental health and coping contribute to work perception. Gauging employee work perception is traditionally done through an employee survey in many organizations to identify and remediate potential issues, such as potential risks for problems in team interaction or work achievement, which may affect work functioning or productivity [46]. The positive perception of work is important for a good work environment [1].

Mental health problems and workplace problems often occur together in workplace environments, and they affect work ability. Higher stress perception is associated with lower job satisfaction and poor work ability [7-9]. Persons with general mental disorders often have problems at their workplace [10]. This can result in long periods of sick leave being taken. The problem is very relevant for rehabilitation, as about $30 \%$ of the general (working) population suffer from a mental disorder [11], and there are high risks and rates of disability pensions due to mental disorders $[12,13]$. On the other hand, problems at the workplace might contribute to mental health problems. High or adverse work demands are associated with a 
higher risk of stress-related symptoms, such as anxiety or depression symptoms [14-17]. They may also affect physiological systems, such as blood pressure, sleep, or biomarkers [18-21].

One specific mental health problem which may explain work perception is workanxiety. In contrast to general mental health problems which affect all domains of live, workanxiety is a specific anxiety related with the workplace. It comes along with work-directed avoidance behavior. Work-anxiety has been empirically distinguished from general mental health problems or work load perception [22-24]. In one pilot study it has been found that people with work-anxiety perceive their work more negatively than people with other mental health problems but without work-anxiety [25]. There is the question whether this finding can be replicated.

Work-coping and personal initiative are also considered to influence the perception of work. Given that stress perception varies between individuals [26], a similar work may be perceived differently by different people, depending on qualification level, or mental health status, or specific coping capacities [27]. Studies on return to work have found that subjective coping is a relevant predictor for successful return to work [28]. Also, sick leave cannot be explained by symptoms, but by work-coping capacities [29,30]. Coping has also been targeted in work-directed intervention studies, and they have shown that coping can be improved $[31,32]$.

Personal initiative can be understood as a specific coping behavior. It means to actively cope with arising problems, with intention to reach a good aim [27]. Personal initiative thus may compensate anxiety avoidance tendencies, as it may be accompanied with better perceived control and coping. Personal initiative has been found to be independent from psychosomatic symptom load [33]. Thus, it is assumed, that within people who have mental health problems, there are some with more and some with less personal initiative. 
In sum, empirical and conceptual research has shown that these above described aspects - general mental health problems and specific work-anxiety, personal initiative and specific work-coping - are relatively independent constructs and may all be relevant for work perception.

\section{Constellations of workplace problems and mental health problems at work}

There may be different constellations of workplace problems and mental health problems. Persons may have

a) workplace problems and mental health problems at the same time $(\mathrm{W}+\mathrm{M})$, or

b) workplace problems (in the sense of a Z-diagnosis according to ICD-10 [34] Zdiagnosis mark a health issue that is not an illness but a difficult context condition, e.g. workplace problems) but no mental health problems $(\mathrm{NM}+\mathrm{W})$, or

c) mental health problems but without workplace problems $(\mathrm{NW}+\mathrm{M})$

d) neither workplace problems nor mental health problems (NW+NM).

Given that the subjective work perception is a crucial factor influencing work ability [1,35], and that occupational psychologists need to know who is endangered, these different groups' work perceptions are of interest. This may help to early detect employees at risk, and prevent dysfunctional developments which might lead to sick leave and work disability. In cases of unusual work perception (e.g. above or below average), low threshold preventive action may be applied: The first step may be a conversation with the employee about his/her work tasks (instead about mental health, which may be perceived as a critical topic). This conversation may happen ad hoc or within the frame of regular appraisal interviews. In case a problem is identified, preventive action may be initiated, such as specific training, reframing 
of work tasks, adjustment of work environment, or team support, and may decrease the risk of sick leave [36].

\section{Research Question and Hypothesis}

Until now it is unclear whether persons who report workplace problems and persons who report mental health problems have different perceptions of their work (demands). It is unclear to which amount the mental health problem or the perceived workplace problem, or other, more specific, factors account for work (demands) perception. To clear this is important in respect to intervention approaches: These may focus on intrapsychic mental health processes, or focus on external workplace aspects.

Hypothesis 1. Since research has shown that persons with mental health problems regularly have problems at work [10,13], we assume the following: Persons with mental health problems (M) perceive higher work demands than persons without mental health problems (NM). Persons with mental health problems and workplace problems $(\mathrm{W}+\mathrm{M})$ perceive higher work demands than persons with workplace problems only $(\mathrm{NM}+\mathrm{W})$.

Hypothesis 2. It is an open question to which amount each of the above introduced potential factors of influence (workplace problem, general mental health problem, specific work-anxiety, personal initiative, work-coping) explain variance in work perception. As in a pilot study, work-anxiety played a relevant role [37], it can be assumed that work-anxiety appears as significant contributor to variance explanation also in this present sample.

\section{Methods and Procedure}

To answer the research questions, a heterogeneous sample of persons with and without mental health problems and with and without workplace problems was required. Thus, persons from the working population, and inpatients from a rehabilitation hospital for 
treatment of common mental disorders (excluding severe mental disorders, e.g. schizophrenia), were recruited. All participants were of working age (18-65 years of age). They all filled in the same questionnaire on work perception (JATS [37,38]), work-anxiety (WPS [23]) and coping resources: personal initiative [33] and work-coping (JoCoRi [39]). Participants filled in the questionnaire at one point of time, with informed consent. The study was approved by the ethics committee of the Freie Universität Berlin. Participants were not provided with financial and/or other incentives to partake in the study.

\section{Instruments}

Work (demands) perception. The Job-Anxiety-Trigger-Scale (JATS) was used to measure work (demands) perception. The JATS measures subjective work perception on a non-judgmental, rather descriptive level [37,38]. The 47 items of the self-rating questionnaire represent the exposure to the following stimuli at the workplace: colleagues, supervisors, coworkers, controlling and demands for achievement, third parties, situational dangers and responsibilities and uncontrollable changes. Item examples are: "During my working time, everything I do is monitored (e.g. by camera, investigation, tachograph)", "In this work I must speak in public (e.g. giving a speech, guidance)", "In my work I have high responsibility for other persons." Participants were asked to think of their present (or if unemployed their last) workplace. The level of exposure to those stimuli is rated on a Likert-scale ranging from strongly disagree (0) to strongly agree (4). The reliability of the JATS is satisfactory. In a previous study, internal consistencies ranged from Cronbach's $\alpha=.719$ for the dimension exposure to colleagues to Cronbach's $\alpha=.785$ for the dimension exposure to supervisors [38]. In this present study, Cronbachs alphas range between $\alpha=.684$ to $\alpha=.831$ (Table 1 ). Weak to moderate correlations $(r=.000$ to $r=.546)$ between the dimensions of the JATS and the dimensions of the Short Job Analysis Questionnaire (Kurzfragebogen zur Arbeitsanalyse, 
KFZA [41] show that the questionnaires measure different constructs indicating a good discriminant validity [38]. People from different professional fields show different profiles of work perception on the JATS [38], which supports content validity.

Work-anxiety. The Workplace Phobia Scale (WPS) is a self-rating scale to assess work-anxiety [23]. It comprises 13 items which derive from the dimensions global workanxiety, anticipatory anxiety and phobic avoidance of the Job-Anxiety-Scale (JAS [24]). Item examples of the WPS are: "When imagining having to pass a complete working day at this workplace, I get feelings of panic.", "I had to go on sick leave once or for several times because I could no longer stand the problems at my workplace.” Participants were asked to think of their present (or if unemployed their last) workplace. The level of approval to the items of the WPS is rated on a Likert-scale ranging from strongly disagree (0) to strongly agree (4). The WPS has an excellent internal consistency (Cronbach's $\alpha=.96$ ). Previous studies, including the State-Trait-Anxiety-Inventory and the SCL-90-R, have shown that the scales of the JAS used for the WPS are valid [24]. Based on the convincing psychometric properties of the WPS, the WPS is a reliable and valid screening scale for work-anxiety and work avoidance behavior.

Coping aspects: work-coping. The Job Coping and Return Intention Inventory (JoCoRi [39]) measures different dimensions of active work-coping. Work-related selfcalming and self-instruction behavior (4 items), and active problem-solving and interactions at the workplace (5 items), were explored. Item examples are: "When I get nervous or stressed at work, I can calm myself down.", "I can tolerate that I do not feel my best at work all the time.", "When a conflict arises at work, I address it, or I help actively to solve the problem." Participants were asked to think of their present (or if unemployed their last) workplace. The items are rated on a Likert-scale ranging from strongly 
disagree (0) to strongly agree (4). Internal consistencies were in previous research ranging from Cronbach's $\alpha=.69$ to Cronbach's $\alpha=.89$. Convergent and divergent validity have been shown by assessing the correlations with parallel and convergent constructs [39].

Coping aspects: personal initiative. The personal initiative (PI) scale [27] assesses to which amount a person sees him/herself as initiative taking and persistent in solving problems. Item examples are: "I take initiative immediately even when others don't.", "Whenever there is a chance to get actively involved, I take it." The participants were asked to rate seven items on their personal initiative on a Likert-scale ranging from strongly disagree (0) to strongly agree (4). The self-reported PI scale for personal initiative has a high internal consistency (Cronbach's $\alpha=.84$ ). The construct validity is convincing; the selfreported scale for personal initiative moderately correlates with partly overlapping concepts, such as action orientation $(r=.35)$ and problem-focused coping $(r=.35)$, and there is no significant correlation between self-reported personal initiative and non-overlapping constructs, such as job satisfaction $(r=.10)$.

Socio-demographics, workplace problem, mental health problem. Additionally to the above described scales, participants were asked for basic socio-demographics (age, professional qualification). Additionally, they were asked whether they suffered from problems at their workplace. Workplace problems were thereby defined as follows: problems with working times, or problems due to frequent absence, or conflicts, or problems with the type of work, or too much work. Participants were also asked whether they suffered from a mental health problem. This self-report on mental health problems has been used in a previous study [40] in which it has been validated with an interview assessment. This self-rating indicates a self-perceived mental health problem and it thus relevant in respect to preventive purposes (e.g. early detection). 


\section{Participants}

The clinical subsample was approached in a typical German psychosomatic rehabilitation clinic, where all types of common mental disorders (anxiety, depression, adjustment and personality disorders) are treated. Consecutive patients were personally asked to fill in the questionnaire anonymously. 218 questionnaires were collected from the clinical sample. The working sample was approached via online questionnaire: The questionnaire was anchored on an online platform for university's surveys (unipark.de). In order to reach a heterogenous sample, the link leading to the survey was placed in internet forums (diverse facebook groups, professional forums) and distributed personally by the authors via snowballing. Requirement for participation was to have working experience with at least a (past) part-time job of 20 hours per week for at least six months. 398 persons clicked the first page and 201 persons from the working population completed the questionnaire.

A total of 384 questionnaires (200 questionnaires being from the clinical sample and 184 being working population) were included in the analysis with complete data. The final sample consisted of $69.5 \%$ women and $30.5 \%$ men. The clinical sample contained $76.5 \%$ women, the employee sample $62 \%$ women. Participants were between 21 and 64 years of age $(M=47.1, S D=11.1)$ and therefore, only slightly older than the average population $(M=43.3$ years [42]).

From the whole sample, $3.1 \%$ did not have a professional qualification, $58.9 \%$ had completed an apprenticeship, and $38 \%$ held a university degree. $85 \%$ of the participants were presently employed, $4.7 \%$ were self-employed, and $2.6 \%$ were employed and self-employed. They worked on average 36.2 hours per week $(S D=9.6) .73 .7 \%$ had been on sick leave during the past 12 months and $26.6 \%$ were presently on sick leave. Only $7.6 \%$ of the whole sample was presently not employed: $6 \%$ were out of work and searching for a job, $1.6 \%$ were 
on time-limited disability pension, in early old age pension or did not want to work. $61.7 \%$ of the participants indicated that they suffered from mental health problems, and $68 \%$ reported to have a workplace problem.

Concerning age, professional qualification and employment status, the persons investigated compare on average to the general population. The patient sample we have investigated is in basic characteristics (age, gender, professional qualification) similar to a prototypical representative sample of patients with mental health problems in outpatient routine (cited from [23,40], Table 1) and similar to typical psychosomatic rehabilitation patients [43]. In comparison to outpatient samples or working population, psychosomatic rehabilitation inpatients from the here investigated sample are more impaired in work aspects (higher sick leave rate, work-anxiety, workplace problems) which is due to the fact that persons with workplace problems and sick leave are a primary indication for a psychosomatic rehabilitation treatment.

Due to the research question, no representative sample is required, but a sample with variance concerning workplace problems and mental health status.

[insert table 1 about here]

\section{Results}

Correlations between JATS dimensions (9-14) and predictors (1-8) are low to moderate, i.e. from $r=-.005$ to $r=.505$, with 45 out of 48 being $r<.400$ (Table 2). Intercorrelations between the predictors (1-8) are from $r=.002$ to $r=-.722$, with 22 out of 28 cases $r<.400$. Inter-correlations between JATS dimensions (9-14) are ranging from $r=.179$ to $r=.555$, with 7 out of 15 being $<.400$ (Table 2 ). There is no multicollinearity problem 
between the predictors (1-8), or between predictors and dependent variables (JATS dimensions).

[insert table 2 about here]

Over all JATS dimensions, persons with mental health problems (M) perceive work demands to a higher degree than people without mental health problems (NM) (Table 3). Persons with workplace problems (W) perceive work demands to a higher degree than persons without workplace problems (NW), but comparable to persons with mental health problems (M) (Table 1). Persons with mental health problems and workplace problems $(\mathrm{M}+\mathrm{W})$ perceive the highest degree of work demands, followed by persons with workplace problems but without mental health problems $(\mathrm{NM}+\mathrm{W})$ (Table 3).

In almost all dimensions of work demands (JATS), several covariates contribute to the understanding of work perception. Thereby, work-anxiety appears most prominent over all JATS dimensions (Table 3+4). The perception of having workplace problems is also consistently significantly associated with the perception of higher work demands. General mental health problems as such, however, do not contribute significantly to variance explanation in work perceptions. Coping aspects only partly contribute to variance explanation, such as in the JATS domain of responsibility and uncertainty (personal initiative), or exposure to third parties (work-coping) (Table 4).

[insert table 3 about here]

[insert table 4 about here]

\section{Discussion}


This is the first study which examined how mental health and personal factors (workcoping, personal initiative, work-anxiety) on the one hand, and workplace problems on the other hand contribute to work perception. Results show that work-anxiety appears as the strongest factor explaining perception of high work demands, whereas general mental health problems do not contribute significantly to variance explanation. Coping capacities (workcoping, personal initiative) do only partly contribute to variance explanation. Comparing this study with other research, there has only recently been a finding that not general mental health problems, but specific work-anxiety is associated with a more negative work perception on the Short Job Analysis Questionnaire ([39] used in [3]). A very first study using the JATS for a description of work demands had also shown that work-anxiety contributes to the work perception [38]. This present study replicates and emphasizes the importance of work-anxiety in a new independent and more heterogeneous sample: specific work-anxiety is more critical in explaining variance in work demands perceptions than having a general (not-workplacerelated) mental health problem. Work-anxiety is also more critical than coping capacities such as work-coping or general personal initiative.

Thus, in rehabilitation practice specifically persons with work-anxiety can be expected to perceive and report higher work demands. Persons with work-anxiety who are still at work may be approached by routinely asking employees for work perception, e.g. within the frame of occupational health surveys, or mental hazard analysis [4-6]. This may overcome fear of stigmatization which could arise when employees would be asked for reporting mental health problems or even work-anxiety. Also, it may open ways to approaching these employees who report their work demands very different than other employees with the same work.

There may be different options for strengthening mental health and improving mental work ability: training people's coping capacities, reducing mental symptom load, or 
modifying a person's perception of work demands $[31,32,25]$. Based on the results of this study, work-anxiety should be considered when examining reasons for problematic work perception, especially when the employee is often or long on sick leave. Training of specific work-coping and early interventions are necessary for facilitating a return to work $[25,44]$.

\section{Limitations and Further Research}

From this cross-sectional study, we have learnt about the relationships of work perception and different personal factors, and thereby differentiating general mental health problems and work-anxiety. In future research, subgroup investigations may be beneficial: It may be cleared which work demands are more or less appropriate for persons with specific characteristics, e.g. work-anxiety, or specific capacity deficits. This might be done designing workplaces that fit the individual employee's capacities. E.g. a person with a severe social phobia who has to work in a front office most of a working day might feel overtaxed by this and come on sick leave, while s/he may be perfect when the work task is answering emails. The individual perspective may need more attention in work design research, where until now this need in the sense of person-job(demand)-fit is not in focus [45]. We need to find ways to earlier identify risk persons and find ways to keep these employees at work and prevent sick leave.

A convenient sample was recruited, according to the correlative questions of research which requires a sample with variance concerning the relevant variables. The study's aim was not to report epidemiological distributions of persons with mental health problems, workplace problems or both. Instead, the characteristics and relations of these groups with work perception were of interest. Only the clinical part of the sample has been diagnosed by physicians, the general population subsample gave self-report on mental health problems. Thus we cannot report results in respect to (specific) mental disorders, but to common mental 
health problems in general. Common mental disorders are regularly comorbid, i.e. confounded by several syndromes $[11,23,40]$.

For early diagnostic and rehabilitative interventions, also the aspect of physiology might be of interest. Research has found that work-anxiety is going along with physiological reactions when specifically being confronted with the workplace or specific work situations $[22,46]$. Similar like "misfitting work demands", also a "physiological reaction" may be a reason to consult an occupational physician. For employees who are affected from workanxiety, it may be easier to speak out that one suffers from work demands or physiological reactions at work, rather than admitting to suffer from work-anxiety.

\section{Conclusion}

The results of this study have practical implications for conceptualizing and conducting exploration of rehabilitation patients as well as interviewing employees (e.g. in mental health hazard analysis). Beside the problematic combination of mental health problems and workplace problems $(\mathrm{M}+\mathrm{W})$, especially work-anxiety is of importance. Workanxiety has been shown in three independent study samples now to play a key role for work perception ([3] using KFZA for work perception; [37] using JATS, KFZA; the present study). Thus, work-anxiety should be considered in rehabilitation diagnostics and interventions in clinical settings, and also at work. The latter may be done within the frame of mental hazard analysis [4-6], or within prevention and inclusion [47-49], or - in cases sick leave is already ongoing - within work-reintegration-interventions [49]. The necessity for action for persons with under-recognized anxiety problems has been outlined [12].

The results of this study also contribute to theory development, as they show that specific work-anxiety, and not general mental health problems per se, affects the work 
perception significantly. Thus, persons with mental health problems and workplace problems $(\mathrm{M}+\mathrm{W})$, and especially persons with specific work-anxiety can be expected to perceive higher work demands. Knowing about the specific concept of work-anxiety, such risk persons can be easier detected and understood, and approached for potential interventions.

\section{Conflict of interest:}

The authors report no conflicts of interest.

\section{Funding:}

There was no financial support for this study from any institution. 


\section{References}

1. Plaisier I, deGraaf R, de Bruin J et al. Depressive and anxiety disorders on-the-job - the importance of job characteristics for good work functioning in persons with depressive and anxiety disorders. Psychiatry Res. 2012;200:382-388. doi: 10.1016/j.psychres.2012.07.016.

2. Van den Berg T, Elders LA, de Zwart BC et al. The effects of work-related and individual factors of the Work Ability Index: a systematic review. Occup Environ Med. 2009;66:211-220. doi: 10.1136/oem.2008.039883.

3. Muschalla B, Fay D, Linden M. Self-reported workplace perception as indicator of work anxieties. Occup Med. 2016;66:168-170. doi: 10.1093/occmed/kqv160.

4. GDA. Gemeinsame Deutsche Arbeitsschutzstrategie. Leitlinie Beratung und Überwachung bei psychischer Belastung am Arbeitsplatz., Nationale Arbeitsschutzkonferenz (Hrg.): Berlin; 2012.

5. HSE. Health and Safety Executive. Managing the causes of work-related stress. A step-by-step approach using the Management Standards. HSE: London; 2007.

6. INRS. L'institut national de recherche et de sécurité. ED 6140. Évaluer les facteurs de risques psychosociaux : l'outil RPS-DU; 2013.

7. Najder A, Mercz-Kot D, Wójcik A. Relationship between occupational functioning and stress among radio journalists - Assessment by means of the Psychosocial Risk Scale. Int J Occup Environ Health. 2016;29:85-100. doi: 10.13075/ijomeh.1896.00332.

8. Slany C, Schütte S, Chastang JF, et al. Psychosocial work factors and long sickness absence in Europe. Int J Occup Environ Health. 2014;20:16-25.

9. Niedhammer I, Chastang JF, Sultan-Taieb H et al. Psychosocial work factors and sickness absence in 31 countries in Europe. Eur J Pub Health. 2013;23:622-629. doi: 10.1093/eurpub/cks124. 
10. Stansfeld SA, Clark C, Caldwell T et al. Psychosocial work characteristics and anxiety and depressive disorders in midlife: the effects of prior psychological distress. Occup Environ Med. 2008;65:634-642. doi: 10.1136/oem.2007.036640.

11. Wittchen HU, Jacobi F, Rehm J, et al. The size and burden of mental disorders and other disorders of the brain in Europe 2010. Eur Psychopharmacol. 2011;21:655-679. doi: 10.1016/j.euroneuro.2011.07.018.

12. Cornelius B, van der Klink JJ, Brouwer S. et al. Under-recognition and under-treatment of DSMIV classified mood and anxiety disorders among disability claimants. Disabil Rehabil. 2014;36:1161-1168. doi:10.3109/09638288.2013.833310.

13. Vaez M, Rylander G, Nygren A et al. Sickness absence and disability pension in a cohort of employees initially on long-term sick leave due to psychiatric disorders in Sweden. Soc Psychiatr Psychiatric Epidemiol. 2007;42:381-388.

14. Andrea H, Bültmann U, van Amelsvoort LG et al. The incidence of anxiety and depression among employees - the role of psychosocial work characteristics. Depression Anxiety. 2009;26:1040-1048. doi: 10.1002/da.20516.

15. Nieuwenhuijsen K, Bruinvels D, Frings-Dresen M. Psychosocial work environment and stressrelated disorders, a systematic review. Occup Med. 2010;60:277-286. doi: 10.1093/occmed/kqq081.

16. Theorell T, Hammartröm A, Aronsson G et al. A systematic review including meta-analysis of work environment and depressive symptoms. BMC Public Health. 2015;15:738. doi: $10.1186 / \mathrm{s} 12889-015-1954-4$.

17. Bonde JP. Psychosocial factors at work and risk of depression: a systematic review of the epidemiological evidence. Occup Environ Med. 2008;65:428-445. doi: 10.1136/oem.2007.038430.

18. Gilbert-Ouimet M, Trudel X, Bisson C, et al. Adverse effects of psychosocial work factors on 
blood pressure: systematic review of studies on demand-control-support and effort-reward imbalance models. Scand J Work Environ Health. 2014;40:109-132. doi: 10.5271/sjweh.3390.

19. Linton SJ, Kecklund G, Franklin KA. Et al. The effect of the work environment on future sleep disturbances: a systematic review. Sleep Medicine Reviews. 2015;23:10-19. doi: 10.1016/j.smrv.2014.10.010.

20. Magnusson Hanson LL, Chungkham HS, Akerstedt T et al. The role of sleep disturbances in the longitudinal relationship between psychosocial working conditions, measured by work demands and support, and depression. Sleep. 2014;37:1977-1985. doi: 10.5665/sleep.4254.

21. Rosário S, Fonseca JA, Nienhaus A et al. Standardized assessment of psychosocial factors and their influence on medically confirmed health outcomes in workers: a systematic review. J Occup Med Toxicol. 2016;11:19. doi: 10.1186/s12995-016-0106-9.

22. Haines J, Williams CL, Carson JM. Workplace phobia: psychological and psychophysiological mechanisms. Int J Stress Manag. 2002;9:129-145. doi: 10.1080/13548500903207398.

23. Muschalla B, Linden M. Workplace Phobia - A first explorative study on its relation to established anxiety disorders, sick leave, and work-directed treatment. Psychol Health Med. 2009;14:591-605.

24. Muschalla B, Linden M, Olbrich D. The relationship between job-anxiety and trait-anxiety - A differential diagnostic investigation with the Job-Anxiety-Scale and the State-Trait-AnxietyInventory. J Anxiety Dis. 2010;24:366-371. doi: 10.1016/j.janxdis.2010.02.001.

25. Muschalla B, Linden M, Jöbges M. Work-Anxiety and Sickness Absence After a Short Inpatient Cognitive Behavioral Group Intervention in Comparison to a Recreational Group Meeting. J Occup Environ Med. 2016;58:398-406. doi: 10.1097/JOM.0000000000000678.

26. Lazarus RS, Folkman S. Stress, appraisal and coping. Berlin: Springer; 1984.

27. Frese M, Fay D, Hilburger T et al. The concept of personal initiative: Operationalization, reliability and validity in two German samples. JOOP. 1997;70:139-161. 
28. Nigatu YT, Liu Y, Uppal M et al. Interventions for enhancing return to work in individuals with a common mental illness: systematic review and meta-analysis of randomized controlled trials. Psychol Med. 2016;46:3263-3274. doi: 10.1017/S0033291716002269

29. Gatchel R, Polatin PB, Mayer TG et al. Psychopathology and the rehabilitation of patients with chronic low back pain. Arch Phys Med Rehabil. 1994;75:666-670.

30. Linden M, Baron S, Muschalla B. Relationship between work-related attitudes, performance and capacities according to the ICF in patients with mental disorders. Psychopathology. 2010;43:262267. doi: $10.1159 / 000315125$.

31. Cheng C, Kogan A, Chio JH. The effectiveness of a new, coping flexibility intervention as compared with a cognitive-behavioral intervention in managing work stress. Work \& Stress. 2012;26:272-288. doi: 10.1016/j.pec.2014.01.005

32. Gardner B, Rose J, Mason O et al. Cognitive therapy and behavioral coping in the management of work-related stress: An intervention study. Work \& Stress. 2005;19:137-152.

33. Fay D, Frese M. The concept of personal initiative: An overview of validity studies. Hum Performance. 2001;14:97-124.

34. WHO World Health Organization. International Statistical Classification of Diseases and Related Health Problems, 10 ${ }^{\text {th }}$ revision. Geneva: World Health Organization; 1992.

35. De Vries H, Fishta A, Weikert B. et al. Determinants of Sickness Absence and Return to Work Among Employees with Common Mental Disorders: A Scoping Review. J Occup Rehabil. 2017, ahead of print. doi: 10.1007/s10926-017-9730-1.

36. Van Vilsteren M, van Oostrom SH, de Vet HC et al. Workplace interventions to prevent work disabilty in workers on sick leave. Cochrane Database Syst Rev. 2015;5;(10), CD006955. doi: 10.1002/14651858.CD006955.pub3

37. Muschalla B. Is it a case of "work-anxiety" when patients report bad workplace characteristics and low work ability? J Occup Rehabil. 2017;27:106-114. doi: 10.1007/s10926-016-9637-2. 
38. Muschalla B. Berichten Patienten mit psychischen Erkrankungen andere Arbeitsbedingungen als Patienten ohne psychische Erkrankungen? Eine Untersuchung mit dem KFZA und der Job-AngstTrigger-Skala (JATS). Prax Klin Verhaltensmed Rehabil. 2016;98:135-147.

39. Muschalla B, Fay D, Hoffmann K. Entwicklung eines Inventars zur Erfassung arbeitsbezogener Copingfähigkeiten und Rückkehrintention (JoCoRi). Diagnostica. 2016;62:143-156.

40. Muschalla B, Linden M. Workplace phobia, workplace problems, and work ability in primary care patients with chronic mental disorders. J Am Board Fam Med. 2014:27:486-494. doi: 10.3122/jabfm.2014.04.130308.

41. Prümper J, Hartmannsgruber K, Frese M. KFZA. Kurzfragebogen zur Arbeitsanalyse. Zeitschrift für Arbeits- und Organisationspsychologie. 1995;39:125-132.

42. Destatis (2011). Zensus 2011. Statistisches Bundesamt. 02.05.2017 retrieved from https://www.zensus2011.de/SharedDocs/Aktuelles/Ergebnisse/DemografischeGrunddaten.html?n $\underline{\mathrm{n}=3065474}$

43. DRV. Quality Report Rehabilitation Center Seehof 2010. Teltow/Berlin: DRV Bund, 2010

44. Nash-Wright J. Dealing with anxiety disorders in the workplace: importance of early intervention when anxiety leads to absence from work. Prof Case Manag. 2011;16:55-59. doi: 10.1097/NCM.0b013e3181f50919.

45. Parker SK, Morgeson FP, Johns G. One Hundred Years of Work Design research: Looking back and looking forward. JAP. 2017;102:403-420. doi: 10.1037/ap10000106.

46. Payne RL, Fineman S, Jackson PR. An interactionist approach to measuring anxiety at work. J Occup Rehabil. 1982;55:13-25.

47. Bauer JF, Chakraverty V, Niehaus M. Betriebliche Inklusion: Arbeitnehmer mit dauerhaften gesundheitlichen Beeinträchtigungen im Etikettierungs-Ressourcen-Dilemma. Public Health Forum. 2017;25:315-317. 
48. Limm H, Gündel H, Heinmüller M et al. Stress management interventions in the workplace improve stress reactivity: a randomised controlled trial. Occup Environ Med. 2011;68:126-133. doi: 10.1136/oem.2009.054148.

49. Cullen KL, Irvin E, Collie A et al. Effectiveness of Workplace Interventions in Return-to-Work for Musculoskeletal, Pain-Related and Mental Health Conditions: An Update of the Evidence and Messages for Practitioners Journal of Occupational Rehabilitation. 2018; 28: 1-15. doi: 10.1007/s10926-016-9690-x. 
Table 1

Characteristics of the three subsamples from general working population and psychosomatic clinic are shown in the first three columns. Relative frequencies are reported, or means (standard deviation) $(n=384)$. Multivariate analysis of (co)variance with test of significance for main and interaction effects. For comparative purposes, descriptive data from other studies are shown in the two columns on the right.

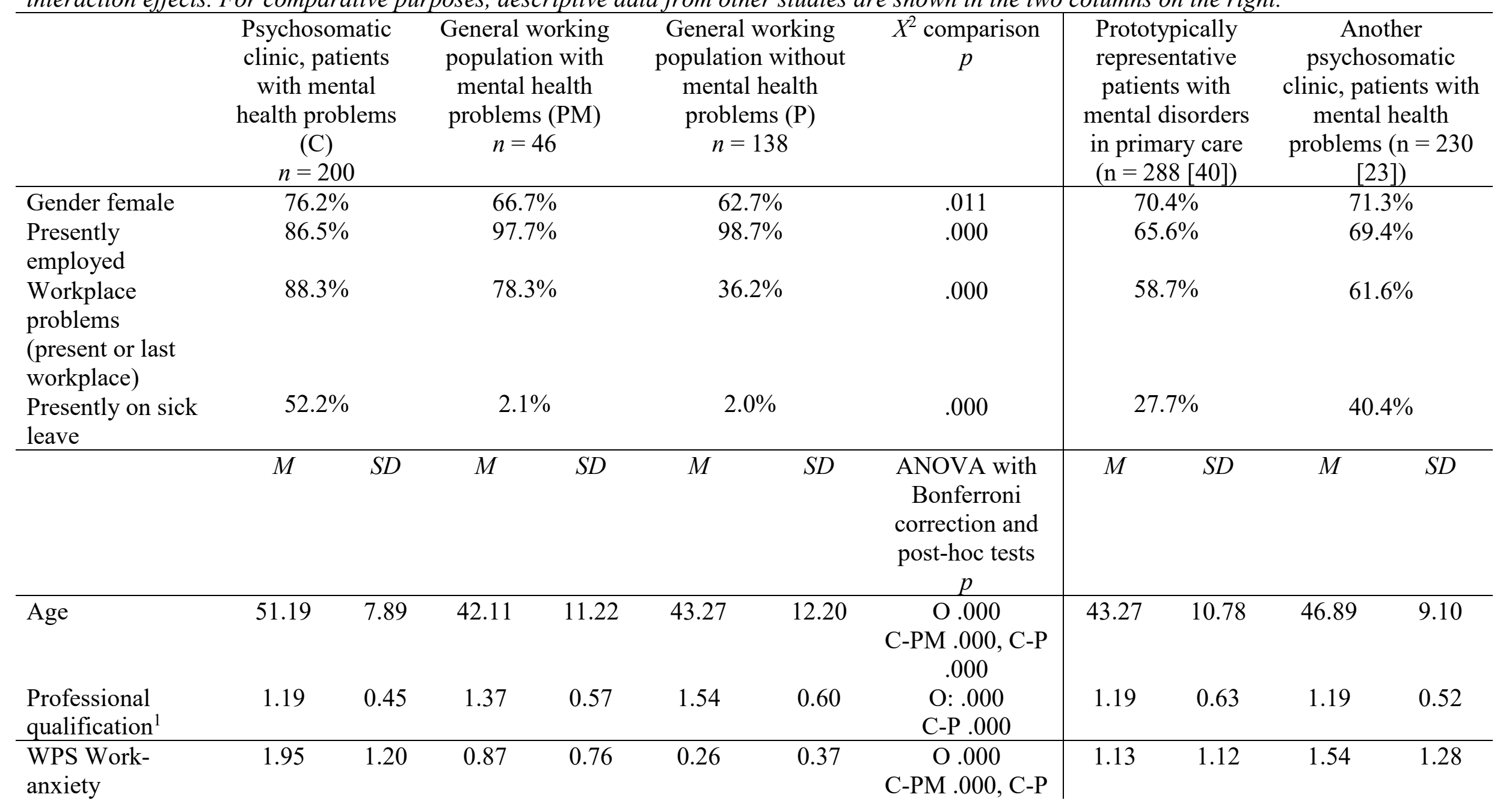




\begin{tabular}{lccccccc|}
\hline $\begin{array}{l}\text { PI Personal } \\
\text { initiative }\end{array}$ & 2.39 & 0.84 & 2.58 & 0.63 & 2.74 & 0.68 & $\begin{array}{c}0.000 \\
\text { C-P .000 } \\
\text { JoCoRi Work } \\
\text { coping }\end{array}$ \\
\end{tabular}

Note: ${ }^{1}$ Professional qualification: $0=$ without professional education, $1=$ professional training, apprenticeship, $2=$ university degree.

$\mathrm{O}=$ Overall significance in group differences in ANOVA 
Table 2

Spearman correlations of all study variables (Spearman correlations). Cronbachs alphas of the interval scaled measures (6-14) are shown in the diagonal.

\begin{tabular}{|c|c|c|c|c|c|c|c|c|c|c|c|c|c|c|}
\hline & 1 & 2 & 3 & 4 & 5 & 6 & 7 & 8 & 9 & 10 & 11 & 12 & 13 & \\
\hline \multicolumn{15}{|l|}{1 Age } \\
\hline 2 Gender & .060 & & & & & & & & & & & & & \\
\hline $\begin{array}{l}3 \text { Professional } \\
\text { qualification }\end{array}$ & .002 & -.056 & & & & & & & & & & & & \\
\hline 4 Mental health problem & $.223 * *$ & $.126^{*}$ & $-.284 * *$ & & & & & & & & & & & \\
\hline 5 Workplace problem & $.126^{*}$ & .077 & $-.137 * *$ & $.506^{* *}$ & & & & & & & & & & \\
\hline 6 WPS Work-anxiety & $.115^{*}$ & .076 & $-.237 * *$ & $.663 * *$ & $.618^{* *}$ & .967 & & & & & & & & \\
\hline 7 PI Personal initiative & -.055 & -.094 & $.145 * *$ & $-.193 * *$ & $-.104 *$ & $-.291 * *$ & .859 & & & & & & & \\
\hline 8 JoCoRi Work-coping & $-.150 * *$ & $-.099 *$ & $.201 * *$ & $-.557 * *$ & $-.474 * *$ & $-.722 * *$ & $.386^{* *}$ & .888 & & & & & & \\
\hline $\begin{array}{l}9 \text { JATS exposure to } \\
\text { colleagues }\end{array}$ & -.082 & .056 & .062 & $.126^{*}$ & $.293^{* *}$ & $.321 * *$ & -.005 & $-.170 * *$ & .745 & & & & & \\
\hline $\begin{array}{l}10 \text { JATS exposure to } \\
\text { supervisors }\end{array}$ & -.032 & .032 & $-.107^{*}$ & $.323 * *$ & $.411 * *$ & $.505^{* *}$ & $-.106^{*}$ & $-.390 * *$ & $.501 * *$ & .831 & & & & \\
\hline $\begin{array}{l}11 \text { JATS exposure to } \\
\text { third parties }\end{array}$ & -.041 & .025 & $.153 * *$ & $.145^{* *}$ & $.213 * *$ & $.224 * *$ & .069 & -.038 & $.289 * *$ & $.179 * *$ & .733 & & & \\
\hline $\begin{array}{l}12 \text { JATS controlling and } \\
\text { demands for achievement }\end{array}$ & -.041 & -.033 & $-.100 *$ & $.271^{* *}$ & $.320 * *$ & $.476^{* *}$ & $-.128 * *$ & $-.296 * *$ & $.401 * *$ & $.555^{* *}$ & $.351 * *$ & .771 & & \\
\hline $\begin{array}{l}13 \text { JATS exposure to } \\
\text { situational dangers }\end{array}$ & .035 & $.141 * *$ & -.065 & $.263 * *$ & $.243 * *$ & $.351 * *$ & .068 & $-.211 * *$ & $.199 * *$ & $.199 * *$ & $.481 * *$ & $.265 * *$ & .763 & \\
\hline
\end{tabular}


Table 3

Comparison of degree of perceived workplace and work demands in a $2 * 2$-design of conditions with „, workplace problems “ and „,mental health problems ". Means (standard deviation) are reported $(n=384)$. Multivariate analysis of (co)variance with test of significance for main and interaction effects.

\begin{tabular}{|c|c|c|c|c|c|c|c|c|c|c|c|c|c|}
\hline \multirow[t]{2}{*}{ Conditions } & \multirow[b]{2}{*}{$n$} & \multicolumn{2}{|c|}{$\begin{array}{l}\text { JATS Exposure to } \\
\text { colleagues }\end{array}$} & \multicolumn{2}{|c|}{$\begin{array}{l}\text { JATS Exposure } \\
\text { to supervisors }\end{array}$} & \multicolumn{2}{|c|}{$\begin{array}{l}\text { JATS Exposure } \\
\text { to third parties }\end{array}$} & \multicolumn{2}{|c|}{$\begin{array}{l}\text { JATS Controlling } \\
\text { and demands for } \\
\text { achievement }\end{array}$} & \multicolumn{2}{|c|}{$\begin{array}{l}\text { JATS Exposure } \\
\text { to situational } \\
\text { dangers } \\
\end{array}$} & \multicolumn{2}{|c|}{$\begin{array}{l}\text { JATS Exposure } \\
\text { to responsibility } \\
\text { and uncertainty }\end{array}$} \\
\hline & & $M$ & $S D$ & $M$ & $S D$ & $M$ & $S D$ & $M$ & $S D$ & $M$ & $S D$ & $M$ & $S D$ \\
\hline \multicolumn{14}{|l|}{ Simple conditions } \\
\hline $\begin{array}{l}\text { No mental health } \\
\text { problem (NM) }\end{array}$ & 147 & 1.60 & 0.76 & 1.23 & 0.86 & 1.12 & 0.96 & 0.82 & 0.57 & 0.30 & 0.55 & 1.30 & 0.80 \\
\hline $\begin{array}{l}\text { Mental health } \\
\text { problem (M) }\end{array}$ & 237 & 1.82 & 0.89 & 1.97 & 1.17 & 1.44 & 1.12 & 1.27 & 0.83 & 0.55 & 0.65 & 1.64 & 0.91 \\
\hline $\begin{array}{l}\text { No workplace } \\
\text { problem (NW) }\end{array}$ & 123 & 1.40 & 0.77 & 1.06 & 0.76 & 0.98 & 0.89 & 0.77 & 0.62 & 0.23 & 0.37 & 1.14 & 0.74 \\
\hline $\begin{array}{l}\text { Workplace problem } \\
\text { (W) }\end{array}$ & 261 & 1.89 & 0.84 & 1.98 & 1.13 & 1.48 & 1.11 & 1.98 & 1.13 & 0.56 & 0.69 & 1.68 & 0.89 \\
\hline \multicolumn{14}{|l|}{ Conditions combined } \\
\hline $\mathrm{NM}+\mathrm{NW}$ & 90 & 1.47 & 0.77 & 1.04 & 0.73 & 1.00 & 0.90 & 0.73 & 0.56 & 0.20 & 0.36 & 1.18 & 0.74 \\
\hline $\mathrm{NM}+\mathrm{W}$ & 57 & 1.82 & 0.70 & 1.53 & 0.96 & 1.31 & 1.02 & 0.97 & 0.57 & 0.45 & 0.73 & 1.48 & 0.86 \\
\hline $\mathrm{NW}+\mathrm{M}$ & 33 & 1.24 & 0.78 & 1.09 & 0.58 & 0.92 & 0.86 & 0.89 & 0.76 & 0.31 & 0.37 & 1.02 & 0.74 \\
\hline $\mathrm{W}+\mathrm{M}$ & 204 & 1.91 & 0.88 & 2.11 & 1.15 & 1.53 & 1.13 & 1.33 & 0.82 & 0.59 & 0.67 & 1.74 & 0.89 \\
\hline & $\begin{array}{l}\text { Multivaria } \\
\text { te effects } \\
\text { Pillais's } \\
\text { Trace } p\end{array}$ & \multicolumn{12}{|c|}{ Effects of univariate analysis } \\
\hline & & $\mathrm{F}(1,384)$ & $p$ & $\mathrm{~F}(1,384)$ & $p$ & $\mathrm{~F}(1,384)$ & $p$ & $\mathrm{~F}(1,384)$ & $p$ & $\mathrm{~F}(1,384)$ & $p$ & $\mathrm{~F}(1,384)$ & $p$ \\
\hline Age & .023 & 7.71 & .006 & 8.69 & .003 & 2.44 & .119 & 2.42 & .121 & 4.02 & .046 & 2.39 & .123 \\
\hline Gender & .000 & 1.21 & .027 & 0.036 & .850 & 0.51 & .474 & 3.80 & .052 & 1.91 & .168 & 11.51 & .001 \\
\hline Professional & .000 & 7.92 & .005 & 0.018 & .894 & 15.48 & .000 & 0.13 & .718 & 0.017 & .896 & 7.69 & .006 \\
\hline
\end{tabular}




\begin{tabular}{|c|c|c|c|c|c|c|c|c|c|c|c|c|c|}
\hline $\begin{array}{l}\text { Mental health } \\
\text { problem }\end{array}$ & .776 & 1.23 & .269 & 0.012 & .912 & 1.18 & .278 & 0.038 & .845 & 0.010 & .753 & 0.010 & .921 \\
\hline Workplace problem & .001 & 9.88 & .002 & 9.57 & .002 & 6.98 & .009 & 0.75 & .387 & 3.52 & .061 & 7.99 & .005 \\
\hline $\begin{array}{l}\text { Mental health } \\
\text { problem }\end{array}$ & .678 & 0.247 & .620 & 0.209 & .648 & 0.25 & .615 & 1.10 & .295 & 0.210 & .647 & 0.067 & .797 \\
\hline WPS Work-anxiety & .000 & 23.92 & .000 & 36.56 & .000 & 19.54 & .000 & 73.02 & .000 & 12.54 & .000 & 40.29 & .000 \\
\hline PI Personal initiative & .013 & 1.05 & .306 & 0.266 & .606 & 0.96 & .327 & 1.09 & .295 & 0.000 & .991 & 8.23 & .004 \\
\hline $\begin{array}{l}\text { JoCoRi Work- } \\
\text { coping }\end{array}$ & .019 & 0.798 & .372 & 1.04 & .308 & 9.78 & .002 & 1.93 & .166 & 0.015 & .903 & 2.41 & .121 \\
\hline
\end{tabular}


Table 4

Linear regression analysis for explaining variance in the multifactorial process of workplace- and work demand perception

\begin{tabular}{|c|c|c|c|c|c|c|c|c|c|c|c|c|}
\hline \multirow{2}{*}{$\begin{array}{l}\text { Potential influencing } \\
\text { factors } \\
\text { model }\end{array}$} & \multicolumn{2}{|c|}{$\begin{array}{c}\text { JATS Exposure to } \\
\text { colleagues }\end{array}$} & \multicolumn{2}{|c|}{$\begin{array}{l}\text { JATS Exposure } \\
\text { to supervisors }\end{array}$} & \multicolumn{2}{|c|}{$\begin{array}{l}\text { JATS Exposure } \\
\text { to third parties }\end{array}$} & \multicolumn{2}{|c|}{$\begin{array}{l}\text { JATS Controlling } \\
\text { and demands for } \\
\text { achievement }\end{array}$} & \multicolumn{2}{|c|}{$\begin{array}{l}\text { JATS Exposure } \\
\text { to situational } \\
\text { dangers }\end{array}$} & \multicolumn{2}{|c|}{$\begin{array}{l}\text { JATS Exposure } \\
\text { to responsibility } \\
\text { and uncertainty }\end{array}$} \\
\hline & $\begin{array}{l}R^{2} \\
.177\end{array}$ & $\begin{array}{c}p \\
.000\end{array}$ & $\begin{array}{c}R^{2} \\
.309\end{array}$ & $\begin{array}{c}p \\
.000\end{array}$ & $\begin{array}{l}R^{2} \\
.147\end{array}$ & $\begin{array}{c}p \\
.000\end{array}$ & $\begin{array}{l}R^{2} \\
.286\end{array}$ & $\begin{array}{c}p \\
.000\end{array}$ & $\begin{array}{l}R^{2} \\
.133\end{array}$ & $\begin{array}{c}p \\
.000\end{array}$ & $\begin{array}{l}R^{2} \\
.241\end{array}$ & $\begin{array}{c}p \\
.000\end{array}$ \\
\hline predictors & Beta & $p$ & Beta & $p$ & Beta & $p$ & Beta & $p$ & Beta & $p$ & Beta & $p$ \\
\hline Age & -.141 & .004 & -.133 & .003 & -.082 & .099 & -.074 & .104 & -.099 & .047 & -.070 & .134 \\
\hline Gender & .050 & .288 & -.011 & .792 & .028 & .556 & -.077 & .082 & .075 & .122 & -.154 & .001 \\
\hline $\begin{array}{l}\text { Professional } \\
\text { qualification }\end{array}$ & .144 & .003 & .010 & .830 & .205 & .000 & .014 & .763 & -.001 & .982 & .117 & .013 \\
\hline $\begin{array}{l}\text { Mental health } \\
\text { problem }\end{array}$ & -.060 & .343 & .015 & .794 & .083 & .199 & -.001 & .982 & .016 & .808 & .000 & .997 \\
\hline Workplace problem & .200 & .001 & .171 & .001 & .147 & .013 & .056 & .301 & .116 & .049 & .155 & .005 \\
\hline WPS Work-anxiety & .359 & .000 & .403 & .000 & .327 & .000 & .563 & .000 & .285 & .000 & .463 & .000 \\
\hline PI Personal initiative & .048 & .346 & .021 & .652 & .055 & .291 & -.048 & .319 & -.005 & .921 & .141 & .004 \\
\hline $\begin{array}{l}\text { JoCoRi Work- } \\
\text { coping }\end{array}$ & .074 & .289 & -.062 & .330 & .211 & .003 & .097 & .140 & .028 & .699 & .116 & .082 \\
\hline
\end{tabular}

